\title{
SPONTANEOUS HAEMORRHAGE FROM THE INTERNAL CAROTID ARTERY IN A CHILD
}

\author{
BY \\ BRIAN WEBB and B. H. PICKARD \\ From King's College Hospital, London
}

(RECEIVED FOR PUBLICATION JULY 27, 1959)

The case described below shows a child in whom there was a spontaneous haemorrhage from the internal carotid artery in relation to a para-pharyngeal abscess.

\section{Case Report}

A boy aged 7 was admitted to hospital after having vomited a small quantity of blood on two occasions during the preceding day without warning or preceding nausea. For six days he had been ill with a sore throat, lassitude and malaise, while the left side of his face and neck had developed a swelling which suggested a diagnosis of mumps.

The boy was pale and inert. He showed a mild pyrexia $\left(100 \cdot 2^{\circ} \mathrm{F}\right.$.) while his pulse was 120 per minute and blood pressure 120/80. A red swelling was visible in the left wall of the pharynx but its extent was not defined as trismus limited inspection. The lymph nodes along the left jugular vein were enlarged.

Three hours after admission a copious haemorrhage occurred. An observer related that the child neither coughed nor vomited but that the blood seemed to well up from the throat.

An immediate operation was deemed necessary and performed by Mr. R. S. Lewis. Under anaesthesia the swelling in the left of the pharynx was confirmed and found to extend from the level of the soft palate down to the epiglottis. The overlying mucous membrane was not discoloured by ecchymosis or inflammation. It bore a ragged opening below and behind the left tonsil leading into a cavity containing blood clot.

An incision was made along the anterior border of the left sternomastoid muscle; the soft tissues were indurated and stiffened while the exposure of the left external carotid artery was impeded by enlarged lymph nodes. The short length of external carotid artery exposed allowed ligature below the origin of the superior thyroid artery.

During the ensuing night a small haemorrhage occurred, but for the next 36 hours the child improved and there was no bleeding until suddenly two days after operation this boy, without warning, lost two or three pints of blood in a cascade from his mouth in three minutes, quickly becoming unconscious, pale and pulseless.
A blood transfusion was started and the child was taken to theatre where the wound was re-opened and the left common carotid artery was divided between ligatures. Three pints of blood were transfused.

Next morning the boy was sitting up in bed cutting paper flags although examination showed signs of a mild right hemiplegia with slight weakness in the right limbs, an accentuated right ankle jerk and extensor plantar response.

During the next 12 hours the child slowly lost consciousness and remained in coma for 48 hours. To preserve the cerebral circulation from spasm and thrombosis Priscol and heparin were given and both stellate ganglia were injected with Xylocain $(1.5 \mathrm{ml}$. of a $2 \%$ solution).

Recovery of his mental state was gradual. For the next five days he was half conscious and when discharged two weeks later he was fully conscious but showed an emotional lability and lack of concentration. The only neurological sign was slight right facial weakness.

Later reports of his schooling show that, although showing imagination, he was backward at first through lack of reasoning power, but that he has now caught up with his fellows.

\section{Discussion}

The severity of the haemorrhages, especially the last, showed that a major artery was involved. That bleeding recurred after ligation of the external carotid artery and was controlled by ligature and division of the common carotid artery showed that the bleeding vessel was the internal carotid artery. The section of the common carotid artery removed the sympathetic supply to the distal part, preventing spasm and minimizing ischaemic changes in the brain (Rogers, 1947). Although knowledge of the site of bleeding would have suggested the common carotid artery for ligature in the first instance, it is doubtful if this alone would have arrested the haemorrhage in view of the free collateral circulation through the branches of the external carotid artery.

This case is notable in having by the two ligatures 
effected complete arrest of blood flow into the left internal carotid artery with little, if any, permanent change in the brain. In the recorded cases (Wood, 1953) $30 \%$ of such cases ended fatally or showed brain damage.

Finally this case stresses the nearness of the internal carotid artery to the pharynx. It may lie as little as $2 \mathrm{~mm}$. below the mucous membrane.

Recent literature shows few cases in which a carotid artery was ligated for spontaneous rupture of the internal carotid artery; one was described by Woodruff in 1945 and one by Beck in 1947.

On the other hand, Salinger in 1934 described over 200 cases of abscess in relation to the pharynx, of which 13 required ligation of one carotid artery.

We thank Mr. R. S. Lewis and Dr. Mary Wilmers for permission to publish this case.

\section{REFERENCES}

Beck, August L. (1947). Deep neck infection. Ann. Otol. (St. Louis), 56, 439.

Rogers, Lambert (1947). Ligature of arteries, with particular reference to carotid occlusion and the circle of Willis. Brit. J. Surg., 35, 43.

Salinger, Samuel (1934). Hemorrhage from pharyngeal and peritonsillar abscess. Laryngoscope (St. Louis), 44, 765.

Wood, Golding P. H. (1953). Ligation of the carotid vessels. J. Laryng., 67, 284.

Woodruff, George H. (1945). Massive pharyngeal hemorrhages. Ann. Otol. (St. Louis), 54, 202. 